\title{
Development of a new temperature-controlled oedometer
}

\author{
Andrew Kirkham ${ }^{1 *}$, Aikaterini Tsiampousi ${ }^{1}$, and David Potts ${ }^{1}$ \\ ${ }^{1}$ Department of Civil and Environmental Engineering, Imperial College London, United Kingdom
}

\begin{abstract}
A new temperature-controlled oedometer has been designed at Imperial College London and commissioned to investigate the thermo-hydro-mechanical behaviour of soils. Under oedometric conditions, temperature can be varied between $5^{\circ} \mathrm{C}$ and $70^{\circ} \mathrm{C}$, by submerging the specimen in a temperature-controlled water bath. This temperature range is appropriate for the proposed applications of the research: design of ground-source heating/cooling systems, and design of geological disposal facilities for nuclear waste. In this paper, an overview of the new equipment is given: its design, development, and calibration. First, the literature on temperature-controlled oedometer schemes is reviewed. A description of the equipment follows, with further details on the innovations and limitations of this design. As the equipment has been modified and improved over the course of the research, so too has the calibration procedure. These developments are discussed, again with the focus on innovations and limitations. Finally, a test programme and preliminary results are presented, for saturated KSS, an artificial mixture of kaolin clay, silt, and sand. These include isobaric (constant-pressure) heating tests, for a variety of loading histories. Overconsolidation ratio is found to affect the thermally-induced volume change.
\end{abstract}

\section{Introduction}

A new, temperature-controlled oedometer has been developed at Imperial College London to provide highquality data relating to the thermo-hydro-mechanical behaviour of soils.

The paper is organised as follows: First, there is a review of other temperature-controlled oedometer schemes from the literature, focussing on key developments, and specific aspects of soil behaviour. Next, the design and development of the new temperature-controlled oedometer at Imperial College London is outlined, followed by the calibration of the equipment. A selection of test results is presented, then some concluding remarks.

This research has a range of potential applications, relevant to the most important issue facing the world today - climate change. First, ground source heating/cooling systems, which can be used to heat and cool buildings in a sustainable way, without burning fossil fuels. This temperature-controlled oedometer can be used for testing soils at above and below ambient temperature, and so is able to simulate both the heating and cooling modes of such systems. Second, nuclear power, which as a carbon-neutral fuel, may play a part in the future energy mix, particularly during the transition from fossil fuels to renewable, sustainable energy. Deep geological repositories (or geological disposal facilities) are proposed for the permanent, safe, disposal of highly radioactive nuclear waste. As part of a system of multiple, passive, natural and engineered barriers, lowpermeability swelling clay will be used as the buffer between the vitrified waste and the surrounding host rock. This clay will be subjected to complex thermohydro-mechanical actions due to heat emitted from the cooling waste, and water infiltration through the host rock.

This research, and the new equipment, forms part of a larger, long-term expansion of the thermal laboratory testing capabilities within the Geotechnics section at Imperial College London. A temperature-controlled triaxial cell has been developed by Martinez Calonge [1], and a suction-controlled oedometer cell has been developed by Mantikos [2]. The latter is based on a similar, complementary, design to the temperaturecontrolled oedometer, which will allow the future development of a combined temperature- and suctioncontrolled oedometer, for testing the effect of temperature on unsaturated soils. In the current research, only saturated soils are tested.

The tested material is fully saturated KSS slurry, an artificial mixture of kaolin clay, silt, and sand. It was chosen because of its relatively high permeability (compared to high-montmorillonite content swelling clays such as bentonite). This reduces testing duration and allows thicker specimens to be tested, which enables thermally-induced strains to be measured with greater accuracy.

\section{Temperature-controlled oedometers}

The pioneering research involving temperaturecontrolled oedometers was done in the USA. Starting with Gray [3], these early schemes (Finn [4], Paaswell [5] and Plum and Esrig [6]) focused on the issue of the

\footnotetext{
* Corresponding author: adk10@ic.ac.uk
} 
difference in temperature between the laboratory test conditions, and the in-situ conditions. Oedometer tests were performed in order to determine the effect of temperature on the one-dimensional consolidation characteristics of the soil, which can be used to determine the rate and magnitude of settlement under load.

Beginning in the late $1980 \mathrm{~s}$, the potential use of saturated clay deposits for heat energy storage became a subject of academic research. Early research in this topic was performed in Sweden, by Eriksson [7], Tidfors and Sällfors [8] and Moritz [9]. Again, oedometer tests were performed, this time to understand what effect temperature changes would have on settlement.

Around this time also, the use of swelling clays as buffer materials in geological disposal facilities was first investigated. Towhata et al. [10] was the first to perform thermal tests on bentonite, and many subsequent schemes have focused on this application [11-15].

More recently, to reduce energy costs and environmental impact, understanding the effect of ground source heat pumps (GSHPs) and energy foundations has been of interest. A variety of soils have been tested for this application, including kaolin clay [16], Bonny silt [17] and Bangkok sand [18].

The first true temperature-controlled oedometer was arguably that of Paaswell [5]. Previous schemes [3, 4] used conventional oedometers in temperature-controlled rooms. Using built-in heaters, it enabled testing at much higher temperatures. The first temperature-controlled oedometer which measured pore-pressure was that of McGinley [19]. The research of Towhata et al. [10], although not notable in terms of equipment design or calibration procedure, was a clear advancement on previous schemes in terms of the broad scope of the testing programme. This was the first scheme to measure the effect of temperature on the equipment itself. The first oedometer to control both suction and temperature was that of Romero [11]. The oedometer design of François et al. [14] is notable for a number of innovations, particularly the use of a pressurised membrane for load application. Although this idea is not new, its application in this context is. More recently, Mon et al. [16] was the first to use bender elements within a temperature-controlled oedometer to measure stiffness. Novel materials have been used in thermal oedometers, including invar, which was chosen for the confining ring by Moritz [9], and Di Donna [20], because of its low thermal expansion coefficient.

\section{Soil behaviour}

Temperature-controlled oedometer schemes have been used to determine the effect of temperature on a wide array of soil properties, and vice versa - the effect of soil properties on thermally-induced volume change. These include: thermally-induced volume change (including effect of over-consolidation ratio, stress level, and repeated thermal cycling), thermally-induced overconsolidation behaviour (pre-consolidation pressure, $\mathrm{p}_{\mathrm{c}}$ ), compression characteristics (compression and swelling indices, $\mathrm{C}_{\mathrm{c}}$ and $\mathrm{C}_{\mathrm{s}}$, coefficient of volume compressibility, $\mathrm{m}_{\mathrm{v}}$, oedometric modulus, $E_{\mathrm{oed}}$, and shear stiffness, $\mathrm{G}$ ), consolidation characteristics (coefficient of primary and secondary consolidation, $\mathrm{c}_{\mathrm{v}}$ and $\mathrm{C}_{\mathrm{a}}$ ) and hydraulic characteristics (coefficient of permeability, $\mathrm{k}$, water retention capacity, and swelling capacity). It is beyond the scope of this paper to discuss all of these, so only those relevant to the test results presented below will be discussed further.

Heating a soil results in volume change. Whether this change will be expansive or contractive depends largely on the stress history. For normally-consolidated and lightly over-consolidated soil, heating causes contraction, whereas at high over-consolidation ratios (OCRs), heating causes expansion $[5,6,10,13,14,17$, $18,21]$. However, even at the same OCR, the experimentally observed response may depend on whether the preceding stage was loading or unloading [10]. There is not a consensus on whether the amount of thermal volume change is affected by stress level. Some studies have found it to be independent of stress level [5, $10,13]$, while others have found a dependence [18].

The effect of thermal cycling has been examined by many studies. Of particular interest is whether thermal volume change resulting from the first heating stage is reversed during subsequent cooling. For normallyconsolidated and lightly over-consolidated soil, contraction due to heating is not reversed by cooling. For highly over-consolidated soil, expansion due to heating may be reversible [13], but some studies have found otherwise [20,21].

The effect of multiple cycles is also of interest, especially in relation to ground source heating/cooling systems. For both normally-consolidated and overconsolidated soils, most permanent thermal volume change occurs during the first heating-cooling cycle. For normally-consolidated and lightly over-consolidated soil, subsequent cycles result in accumulation of permanent volume change, the amount reducing with each cycle. For highly over-consolidated soils, subsequent cycles do not cause any further permanent volume change [17]. Thermal cycling effects were compared for steel and invar confining rings by $\mathrm{Ng}$ [22].

Finally, it is important to note the importance of soil type. Thermal volume change increases with increasing plasticity $[10,20]$. Within the literature for temperaturecontrolled oedometer schemes, a range of different soils are tested - high plasticity swelling clays such as bentonite [10], medium plasticity silty clays [20], silty sands [14], and sand [18], among others.

\section{Design and development}

Certain capabilities are fundamental to all oedometers. They must apply a controlled vertical load. They must restrict displacement of the specimen to the vertical direction only. And they must measure this vertical displacement. In addition to these requirements, the temperature-controlled (TC) oedometer must be able to maintain a controlled temperature. Therefore, it should not be surprising that many of the components of the TC 
oedometer are familiar, even if the full assembly looks quite different to the conventional oedometer.

The equipment is shown schematically in Figure 1, along with a photograph in Figure 2. With reference to Figure 1, components (1) to (4) can be found in any modern electronic oedometer. Load is applied using a computer-controlled stepper-motor within the load frame, via the loading ram. The loading ram is divided into an upper (1) and lower (3) section. Between these is the load cell (2) which is used to measure the current load. This value is fed back to the computer. The computer, using TRIAX software [23], then determines whether any change is required, based on the current and target load. The lower section of the loading ram is much longer than the upper section. This is to allow space for the instrumentation plate (7), above the water-bath lid (9) but below the load cell. The upper section of the loading ram is as short as possible, to minimise the total length of the loading ram. The top-cap (4) is screwed into the lower section of the loading ram.

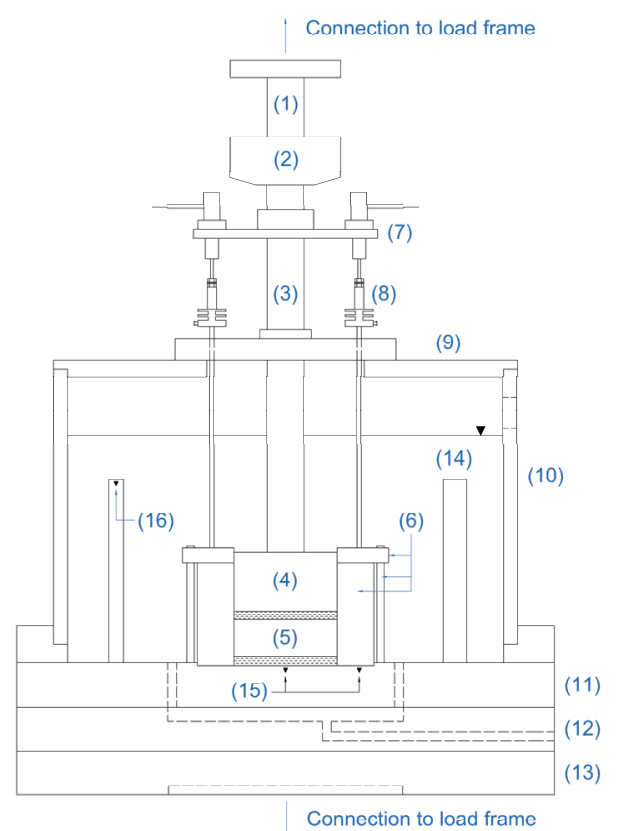

Fig. 1. Temperature-controlled oedometer schematic

(1) Loading ram (upper section)

(2) $10 \mathrm{kN}$ Load cell

(3) Loading ram (lower section)

(4) Top-cap

(5) Soil specimen, between porous stones

(6) Confining ring (including collar and bolts)

(7) Instrumentation plate

(8) Extension pieces for displacement transducers

(9) Three-piece PVC lid

(10) PVC water bath

(11) Upper steel plate

(12) Lower (hollow) steel plate

(13) PVC base

(14) Heater (in brass housing)

(15) Temperature sensors in upper plate

(16) Temperature sensor in water bath (in brass housing)

The tested specimen (5) sits between two porous stones, allowing two-way drainage. There are drainage paths through the top-cap (4) and the upper steel plate (11) for the same purpose. The confining ring (6) prevents lateral displacement of the specimen. It comprises a ring, a collar, and six holding-down bolts.

Displacement is measured with three LVDTs mounted on the instrumentation plate (7). The LVDT core connects to an extension piece (8), which passes through a small hole in the central section of the lid (9) to reach the confining ring collar. Heat dissipators are attached to the extension pieces, just above the lid. The PVC lid (9) and base (13) prevent excessive heat-loss, as well as insulating the instrumentation above the water bath.

The water bath is formed from a PVC cylinder (10), which sits above two stainless-steel plates (11) and (12). A novel feature of this oedometer is the lower plate (12), which has a hollow section directly below the specimen. Water drains down from the water bath, through the upper plate (11), and then spreads out in the hollow section of the lower plate. The water is then pumped out of the lower plate, and back into the water bath. By circulating water below the specimen, it is heated from below as well as from the sides and above. This isotropic heating minimises the temperature gradient across the specimen, which is a potential issue with previous schemes. Temperature is controlled using the water bath surrounding the specimen. The water is heated by three $150 \mathrm{~W}$ electrical heaters (14) within the bath.

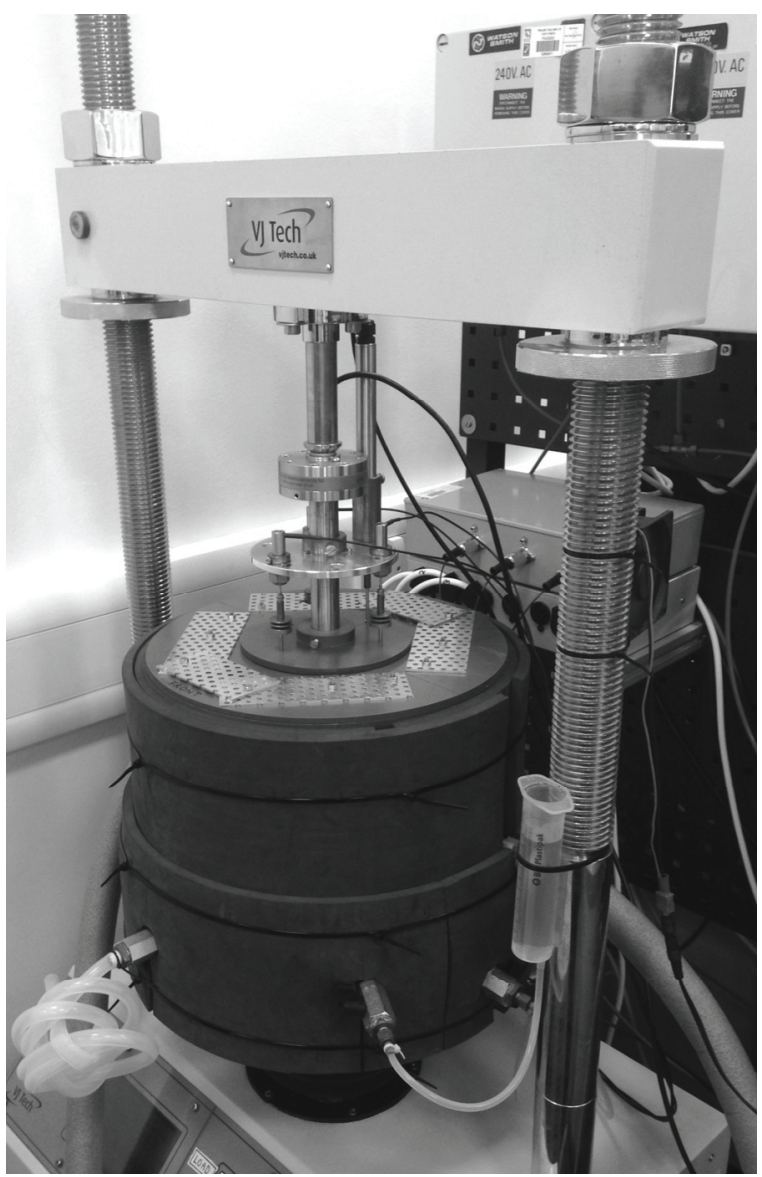

Fig. 2. Temperature-controlled oedometer photograph 
Heating and cooling can also be applied using an external heating/cooling unit, in combination with a custom-built heat exchanger. With this combined system, temperature can be controlled in the range $5^{\circ} \mathrm{C}$ to $70^{\circ} \mathrm{C}$. The maximum temperature is limited by the PVC lid, which begins to deform at temperatures above $70^{\circ} \mathrm{C}$, and the heating rate is limited not by the equipment capability, but by the soil permeability, especially for low permeability clays.

Temperature is measured at three points - two beneath the specimen and confining ring (15) and one within the water bath (16). The measuring instrumentation and the heaters are connected to TRIAX software that can be used to control variables such as temperature, force and displacement.

An annotated schematic showing detail of the confining ring is shown in Figure 3. The ring has an internal diameter of $70 \mathrm{~mm}$ and a height of $70 \mathrm{~mm}$ (not including collar). The maximum possible specimen height is approximately $50 \mathrm{~mm}$. An o-ring sits in a small groove in the side-wall of the top-cap, which helps keep the loading ram vertical, preventing sticking of the topcap and the ring due to tilting effects. It also allows the specimen to be isolated from the water within the bath, so that a controlled back-pressure can be applied. However, friction between the o-ring and the inner surface of the confining ring needs to be measured and accounted for in the interpretation of the results.

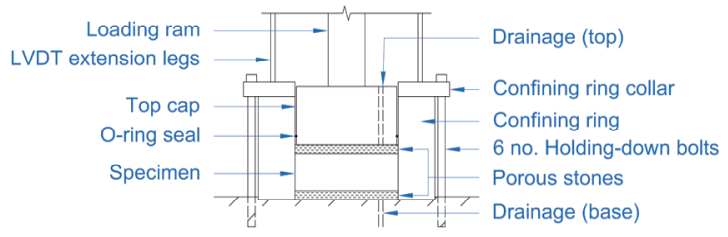

Fig. 3. Confining ring schematic

The upper section of the apparatus is shown schematically in Figure 4. The instrumentation plate is a stainless-steel plate, with six equally-spaced holes for holding the displacement transducers, inclinometers, or other instrumentation.

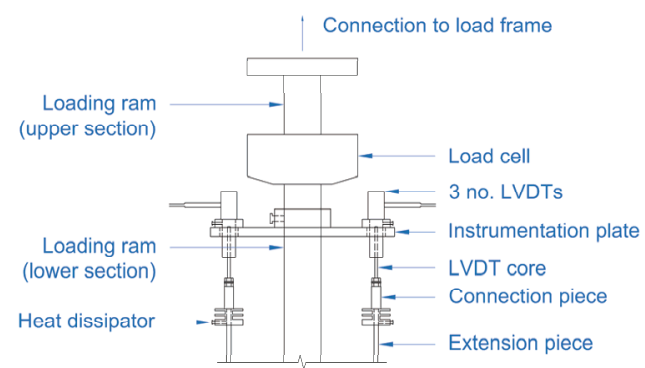

Fig. 4. Instrumentation schematic

The system used for control of sub-ambient temperatures is shown schematically in Figure 5. It comprises four components: the water bath, the heat exchanger, the chiller, and the pump.

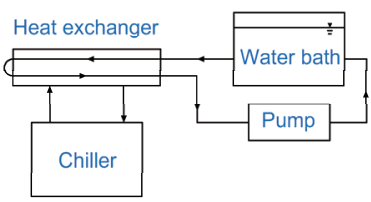

Fig. 5. Chiller system schematic

Water from the bath is continuously circulated through the heat exchanger by the pump, even when the chiller is not in operation. Continuous circulation is required to prevent build-up of high temperatures around the heaters, and to heat the specimen evenly, by circulating water through the hollow base-plate, as described above.

\section{Calibration}

In the development and commissioning of a new piece of laboratory equipment, careful calibration is of extreme importance, but is also complex and time-consuming. François and Laloui [24] described calibration as the most critical issue in the development of their combined temperature- and suction-controlled oedometer. Vega and McCartney [17] wrote that calibration is critical to evaluate the machine deflection of the thermal oedometer during both mechanical loading and subsequent temperature changes.

Temperature has four measurable effects on the apparatus. These are (i) the vertical (thermally-induced) deformation of the apparatus (ii) the radial (thermallyinduced) deformation of the confining ring (iii) the change in the isothermal mechanical response due to loading at different temperatures (iv) the direct effect of temperature on instrumentation.

Initially, the aim was to develop a single calibration for the vertical deformation (i) and (iii), i.e. the thermally-induced deformation (as a function of pressure) and the mechanical deformation (as a function of temperature), to give the equipment deformation as a function of both pressure and temperature. However, for the pressure and temperature range relevant to testing, the mechanical deformation was approximately an order of magnitude greater than the thermally-induced deformation. In addition, there was hysteresis in both components, following loading/unloading or heating/cooling. This meant that the error in the mechanical deformation was large compared to the total thermally-induced deformation, and as such, a combined calibration was not accurate. Instead, for subsequent calibration tests, including those presented below, thermal and mechanical paths were performed without a soil specimen in place, only porous stones. The relevant components of this data were then used to correct the test data - for example, the thermal component, if thermallyinduced volume change was of interest, or the mechanical component, for consolidation behaviour.

The direct effect of temperature on the instrumentation (iv) is almost impossible to quantify. Any instrumentation that is made of materials with nonzero thermal expansion coefficients (i.e. all instrumentation), will be affected to some extent by temperature. This fact was the main driver in the 
decision to isolate the instrumentation from the heat source, as described above. A thermal camera was used to confirm that when temperature within the water bath is at $70^{\circ} \mathrm{C}$, the instrumentation plate, displacement transducers, and load cell remain at ambient temperature.

The radial (thermally-induced) deformation of the confining ring (iii) was not measured, but calculated, based on the thermal expansion coefficient, $\alpha_{\mathrm{v}}$, of stainless-steel. Its effect must be examined in conjunction with the thermal expansion coefficient of the soil. For KSS, the tested material, the thermal expansion coefficient of steel, $\alpha_{\mathrm{v} \text {-steel, }}$, is greater than that of the soil, $\alpha_{\mathrm{v} \text {-soil. }}$ This means, during heating, the lateral expansion of the confining ring is greater than that of the soil. However, due to the applied vertical load, the soil expands laterally to fill the available space, resulting in a reduction in soil height. This reduction in height is not the direct effect of temperature on the soil, but the indirect effect of the differential thermal expansion of the soil and confining ring. During cooling, the lateral contraction of the confining ring is greater than that of the soil, and the soil is compressed laterally, resulting in an increase in the soil height. Again, this increase in height is not the direct effect of temperature. In both cases, a correction is applied by assuming that the soil volume remains constant.

Finally, the calculated void ratio was corrected, taking into consideration the thermal expansion (or contraction) of the solid phase of the soil during heating (or cooling). This correction can have an important effect on the final interpretation of the data, and yet there is a significant range of thermal expansion coefficient values in the literature, even for well-studied minerals. For quartz, Skinner [25] gives an $\alpha_{v}$ range of 34 to $57.6 \times 10^{-6}{ }^{\circ} \mathrm{C}^{-1}$.

\section{Testing}

The tested material was an artificial clay soil, KSS, which was prepared as a slurry by mixing $50 \%$ kaolin clay, $25 \%$ silt, and $25 \%$ sand (by dry weight) at 1.25 times the liquid limit of the soil. Some properties of KSS are given in Table 1. The volumetric thermal expansion coefficient was calculated using the $\alpha_{\mathrm{v}}$ values for kaolin [26] and quartz [27-29]. This is the thermal expansion coefficient for the mineral solids.

Table 1. Properties of KSS

\begin{tabular}{ll}
\hline Property & Value \\
\hline Liquid limit [\%] & 34.5 \\
Plasticity index [\%] & 17.5 \\
Plastic limit [\%] & 17 \\
Specific gravity [-] & 2.63 \\
Volumetric thermal expansion coefficient $\left[{ }^{\circ} \mathrm{C}^{-1}\right]$ & $27 \times 10^{-6}$ \\
\hline
\end{tabular}

The effect of over-consolidation ratio on thermallyinduced volume change was tested by applying a heating/cooling cycle to three specimens at different OCR values. The load/temperature path is shown in Figure 6.
All three specimens were consolidated at $22.5^{\circ} \mathrm{C}$, from a slurry, to $1500 \mathrm{kPa}$ vertical pressure $(\mathrm{A} \rightarrow \mathrm{B})$, then unloaded to (or held constant at) the pressure corresponding to the target OCR value. This pressure was $50 \mathrm{kPa}$ for OCR $=30(\mathrm{~B} \rightarrow \mathrm{D}), 300 \mathrm{kPa}$ for OCR $=$ $5(\mathrm{~B} \rightarrow \mathrm{C})$ or in the case of the normally-consolidated specimen $(\mathrm{OCR}=1), 1500 \mathrm{kPa}$. Next, the specimens were heated to $70^{\circ} \mathrm{C}$, held for 6 hours, then cooled to

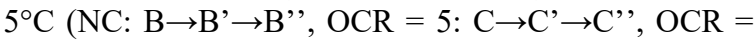
30: $\mathrm{D} \rightarrow \mathrm{D} \rightarrow \mathrm{D}$ '). The heating rate was $2^{\circ} \mathrm{C} / \mathrm{h}$, and the cooling rate was a maximum of $5^{\circ} \mathrm{C} / \mathrm{h}$. At these heating/cooling rates the rate of strain was under $0.01 \% / \mathrm{h}$, which is considered sufficiently slow to ensure drained conditions.

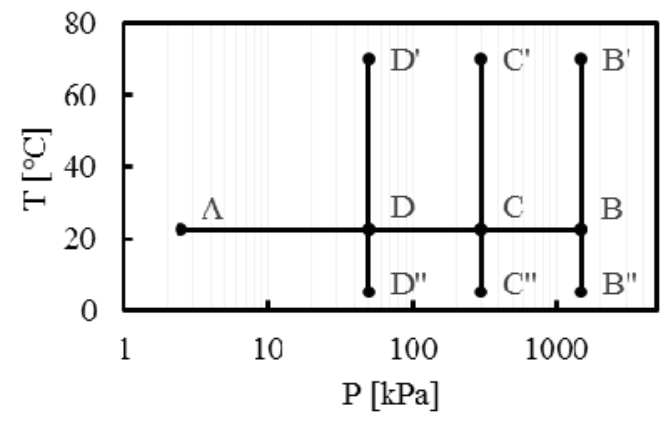

Fig. 6. Testing path, temperature and vertical pressure $\mathrm{OCR}=1: \mathrm{A} \rightarrow \mathrm{B} \rightarrow \mathrm{B}^{\prime} \rightarrow \mathrm{B}^{\prime \prime}$

$\mathrm{OCR}=5: \quad \mathrm{A} \rightarrow \mathrm{B} \rightarrow \mathrm{C} \rightarrow \mathrm{C}^{\prime} \rightarrow \mathrm{C}^{\prime \prime}$

$\mathrm{OCR}=30: \mathrm{A} \rightarrow \mathrm{B} \rightarrow \mathrm{D} \rightarrow \mathrm{D}^{\prime} \rightarrow \mathrm{D}^{\prime \prime}$

\section{Results and discussion}

The results are shown in Figure $7(\mathrm{OCR}=1)$ and Figure $8(\mathrm{OCR}=5$ and $\mathrm{OCR}=30)$ on axes of temperature, $\mathrm{T}$, against volumetric strain, $\varepsilon_{v}$, defined as follows:

$$
\varepsilon_{v}=\Delta V / V_{0}
$$

where $\Delta V$ is the thermally-induced volume change (from point $\mathrm{B}, \mathrm{C}$ or $\mathrm{D}$ ), and $V_{0}$ is the volume at the start of the test (at point A). Note that positive $\varepsilon_{v}$ corresponds to contraction, and negative $\varepsilon_{v}$ to expansion.

The normally-consolidated specimen contracts during heating and subsequent cooling, although the gradient of the cooling path is smaller. The overconsolidated specimens both expand during heating, with the amount of expansion increasing for the higher OCR value. During subsequent cooling, for an OCR of 5 , the specimen contracts. The contraction is less than the expansion during heating, resulting in an overall expansion following the heating/cooling cycle. For an OCR of 30 , there is negligible volume change during cooling, resulting in a greater overall expansion for the heating/cooling cycle than at an OCR of 5. 


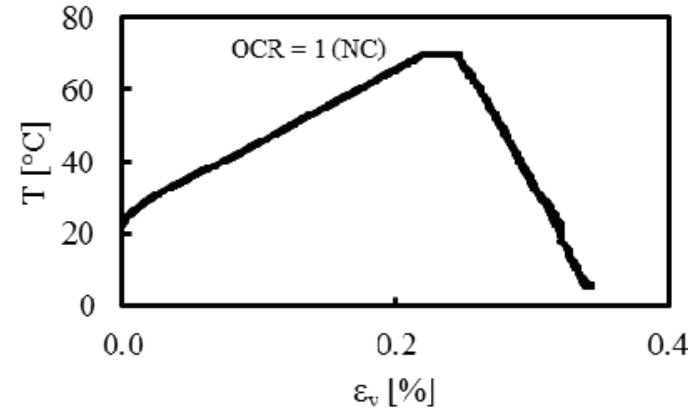

Fig. 7. Thermal strain at OCR 1 (positive $\varepsilon_{\mathrm{v}}=$ contraction)

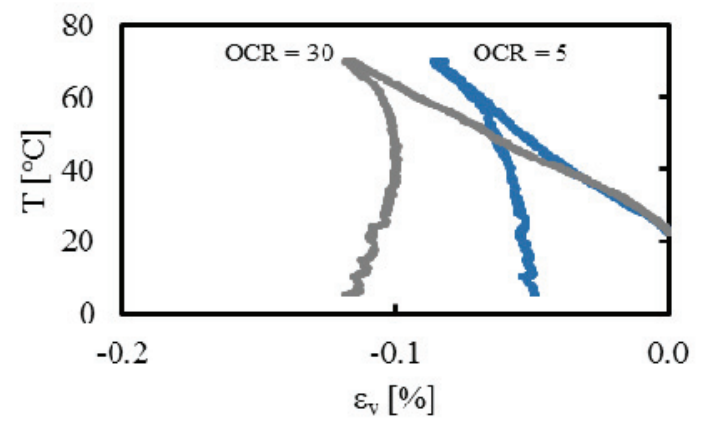

Fig. 8. Thermal strain at OCR $5 \& 30$ (negative $\varepsilon_{\mathrm{v}}=$ expansion)

\section{Conclusions}

A new temperature-controlled oedometer has been designed and developed at Imperial College London, for oedometric testing between $5^{\circ} \mathrm{C}$ and $70^{\circ} \mathrm{C}$.

A review of other temperature-controlled oedometer schemes from the literature shows that these schemes can be used to determine most of the important soil properties. Although the application of the research has changed over time, the results, and the use of temperature-controlled oedometers, remain relevant. This research in particular is relevant to current thermomechanical problems in geotechnical engineering, such as the design of ground-source heating/cooling systems.

Temperature of the tested specimen is controlled with a temperature-controlled water bath. For heating above ambient temperature, the water bath is heated directly using three $150 \mathrm{~W}$ heaters. For cooling below ambient temperature, an external chiller unit is used, in combination with a heat exchanger. Water is continuously circulated through a hollow plate, which minimises the temperature gradient across the specimen.

A full, thermal and mechanical calibration of the equipment has been carried out. Vertical thermal and mechanical deformation is corrected by repeating the full heating/loading path for the proposed test. However, the thermal and mechanical corrections are applied separately, not in combination, because of the much larger magnitude of mechanical strains (and associated error). The instrumentation (load cell and displacement transducers) is raised above the lid of the water bath and in this way isolated from the heat source. The differential, thermal, lateral expansion of the confining ring and soil has been considered in the calculation of the soil volume, as too has the thermal expansion of the solid phase of the soil in the calculation of the void ratio.

An artificial clay, KSS, has been tested. Isobaric heating/cooling tests were performed on normallyconsolidated (NC) or over-consolidated (OC) soil, and the results agree qualitatively with those from the literature. For NC KSS, heating causes contraction. Cooling also causes contraction (albeit less than heating). For OC KSS, heating causes expansion, which increases with OCR. Cooling causes contraction, which is less than the expansion due to heating, and which appears to reduce with OCR.

This research has been supported by the Engineering and Physical Sciences Research Council (EPSRC), through a Doctoral Training Grant (Ref: EP/1855518) awarded to the first author. The authors would like to thank Steve Ackerley, Stef Karapanagiotidis, David Taborda, and Jamie Standing, for their help with the equipment development and data analysis.

\section{References}

1. D. Martínez Calonge. Experimental investigation of the thermo-mechanical behaviour and thermal properties of London clay. PhD. Imperial College London (2017)

2. V. Mantikos. Development of novel apparatus for establishing swelling and water retention characteristics of bentonite. $\mathrm{PhD}$. Imperial College London (2018)

3. H. Gray. Progress report on research on the consolidation of fine-grained soils. 1st Int. Conf. on Soil Mechanics and Foundation Engineering. Massachusetts, USA: p. 138-141 (1936)

4. F. Finn. The effect of temperature on the consolidation characteristics of remolded clay. Symposium on Consolidation Testing of Soils. New Jersey, USA: p. 65-71 (1952)

5. R.E. Paaswell. Temperature effects on clay soil consolidation. Journal of the Soil Mechanics and Foundations Division. 93(3): p. 9-22 (1967)

6. R. Plum, M. Esrig. Effects of temperature on some engineering properties of clay soils. Int. Conf. on Effects of Temperature and Heat on Engineering Behavior of Soils. Washington, D.C., USA: p. 231242 (1969)

7. L. Eriksson. Temperature effects on consolidation properties of sulphide clays. Int. Conf. on Soil Mechanics and Foundation Engineering. Rio de Janeiro, Brazil: p. 2087-2090 (1989)

8. M. Tidfors, G. Sällfors. Temperature effect on preconsolidation pressure. Geotechnical Testing Journal. 12(1): p. 93-97 (1989)

9. L. Moritz. Geotechnical Properties of Clay at Elevated Temperatures. Swedish Geotechnical Institute. Report no. 47 (1995).

10. I. Towhata, P. Kuntiwattanaku, I. Seko, K. Ohishi. Volume change of clays induced by heating as observed in consolidation tests. Soils and Foundations. 33(4): p. 170-183 (1993) 
11. E. Romero. Characterisation and thermo-hydromechanical behaviour of unsaturated Boom Clay: An experimental study. $\mathrm{PhD}$. Universitat Politècnica de Barcelona (1999)

12. M.V. Villar, A. Lloret. Influence of temperature on the hydro-mechanical behaviour of a compacted bentonite. Applied Clay Science. 26(1-4): p. 337350 (2004)

13. H.M. Abuel-Naga, D.T. Bergado, S. Soralump, P. Rujivipat. Thermal consolidation of soft Bangkok clay. Lowland Technology International. 7(1): p. 13$21(2005)$

14. B. François, S. Salager, M. El Youssoufi, D. Ubals Picanyol, L. Laloui, C. Saix. Compression tests on a sandy silt at different suction and temperature levels. Computer Applications in Geotechnical Engineering: p. 1-10 (2007)

15. W.M. Ye, Y.W. Zhang, B. Chen, Z.J. Zheng, Y.G. Chen, Y.J. Cui. Investigation on compression behaviour of highly compacted GMZ01 bentonite with suction and temperature control. Nuclear Engineering and Design. 252(1): p. 11-18 (2012)

16. E.E. Mon, S. Hamamoto, K. Kawamoto, T. Komatsu, P. Moldrup. Temperature effects on geotechnical properties of kaolin clay: simultaneous measurements of consolidation characteristics, shear stiffness, and permeability using a modified oedometer. GSTF International Journal of Geological Sciences (JGS). 1(1): p. 1-10 (2013)

17. A. Vega, J.S. McCartney. Cyclic heating effects on thermal volume change of silt. Environmental Geotechnics. 2(5): p. 257-268 (2015)

18. J. Sittidumrong, A. Jotisankasa, K. Chantawarangul. Effect of thermal cycles on volumetric behavior of Bangkok sand. Geomechanics for Energy and the Environment. 20: p. 100127 (2019)

19. J.M. McGinley. The effects of temperature on the consolidation process of saturated fine-grained soils. PhD. University of Colorado (1983)

20. A. Di Donna, L. Laloui. Response of soil subjected to thermal cyclic loading: experimental and constitutive study. Engineering Geology. 190: p. 65$76(2015)$

21. V. Favero, A. Ferrari, L. Laloui. Thermomechanical volume change behaviour of Opalinus Clay. International Journal of Rock Mechanics and Mining Sciences. 90: p. 15-25 (2016)

22. C.W.W. Ng, Q. Mu, C. Zhou. Effects of boundary conditions on cyclic thermal strains of clay and sand. Géotechnique Letters. 7(1): p. 73-78 (2017)

23. D. Toll. A data acquisition and control system for geotechnical testing. Computing Developments in Civil and Structural Engineering. p. 237-242 (1999)

24. B. François, L. Laloui. An oedometer for studying combined effects of temperature and suction on soils. Geotechnical Testing Journal. 33(2): p. 112$122(2010)$

25. B.P. Skinner. Thermal expansion. Handbook of Physical Constants. p. 75-91 (1966)

26. H.A. McKinstry. Thermal expansion of clay minerals. American Mineralogist: Journal of Earth and Planetary Materials. 50(1-2): p. 212-222 (1965)
27. G. Kaye, T. Laby. Physical and chemical constants. Harlow Longman. p. 273 (1959)

28. W. Flügge. Handbook of engineering mechanics. McGraw-Hill New York (1962)

29. O.W. Eshbach, B.D. Tapley. Eshbach's handbook of engineering fundamentals. John Wiley \& Sons (1990) 